\title{
Editorial: Of Zombies, Endings and Beginnings ...
}

In the Globe and Mail, 6 September 2008, Doug Saunders's column was entitled, "Europe Comes Home to the Shock of a Demographic Bombshell." He opines on the latest Eurostat report, Population and Social Conditions, which predicts that by 2015 the European population will begin to shrink as deaths outnumber births, even taking into account immigration and in the absence of any other changes. Near the end of the column, Mr. Saunders concludes that Canada will face the same woes of an aging population in another 20 years. It is yet another example of "apocalyptic demography."

At the 37th Annual Scientific and Educational Meeting (ASEM) of the Canadian Association on Gerontology (CAG), which was recently held in London, Ontario, I attended a symposium on "Caring for the Aging Population," organized by the Social Economic Dimensions of Aging Population (SEDAP) research group of which I am a member. One of the papers noted that home-health and community support services are preferred by those who receive them and provide excellent service and value for money, but governments continue to under-resource home care. In response, someone from the audience commented that we have been saying these things for 20 years and still governments do not listen.

To paraphrase Robert Evans of the University of British Columbia, we might call both these accounts, "zombies" of gerontology. They are like zombies, which keep rising from the dead and cannot be killed: No matter how much research demonstrates that the aging of a society's population cannot, in and of itself, lead to the collapse of economic, health, or other societal systems or that home care needs to be properly resourced, our messages seem to be ignored or under-valued. How can we end the zombies once and for all? or, maybe somewhat less dramatically, How can we disseminate our messages more broadly and effectively?

As editor-in-chief of the $C J A / R C V$, these are two questions I have thought about often over the past 4 years. One of my partial answers has been to introduce new formats for the publication of research in the $C J A / R C V$. Although I cannot take credit for the innovation, CJA/RCV 24.1 (2005) published a symposium, or what other journals might call a special section on "Aging Well." CJA/RCV 25.1 (2006) introduced a special feature, a full-length article, published both in English and French, synthesizing the findings of a major program of research-in this case, "Integrated Services for Frail Elders (SIPA): A Trial Model for Canada." CJA/RCV 26.3 (2007) introduced a new section, "Policy and Practice Notes." Symposia, special feature articles, and "Policy and Practice Notes" have all been attempts to engage broader audiences, and the $C J A / R C V$ will continue to use these formats in the future because I remain convinced that the CJA/ $R C V$ needs to go beyond the traditional format of research papers if we are to reach wider audiences than we have in the past.

Fast-forward to the annual general meeting of the 37th ASEM of the CAG, where I explained, in my 2008 annual report, that the $C J A / R C V$ faces a number of uncertainties going into the future. At the back of mind, I, however, kept coming back to the key questions of what else can the $C J A / R C V$ do to grow as a journal and to disseminate our messages more broadly and effectively. For me, the answer was to find an international publisher. This is a decision we have now taken, and I will have more to say about the process and our choice in the first issue of 2009.

With this issue, the $C J A / R C V$, therefore, ends its relationship with the University of Toronto Press (UTP). As editor-in-chief, this has been, without a doubt, the most difficult decision I have had to make. Over the four years I have been editor-in-chief, there have been many people at UTP whose service to the $C J A / R C V$ I have greatly appreciated, and I would like to thank all of them. Two of them, however, have been constants in the production of the $C J A / R C V$, and they deserve special mention and thanks, Rosemary ClarkBeattie and Anne Marie Corrigan.

While I cannot guarantee that the decision to move to an international publisher will slay the gerontology zombies I mentioned at the beginning of this editorial, I am confident that the decisions that have been made will bring us a wider audience and new challenges as contributors, readers, and editors of the $C J A / R C V$.

As always, please contact me at mark.rosenberg@ queensu.ca if you have any thoughts about this editorial or any other aspect of the $C J A / R C V$.

Mark Rosenberg

Editor-in-Chief 


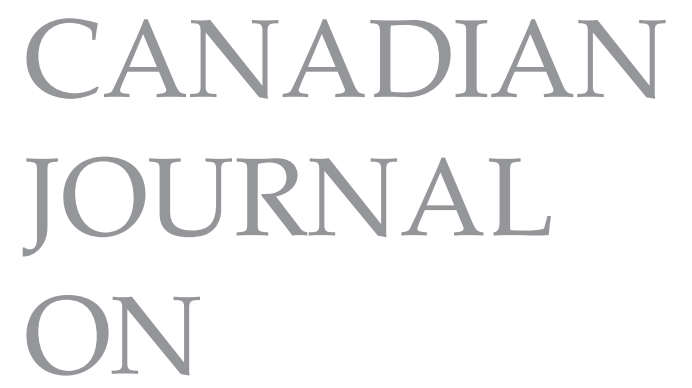

AGING

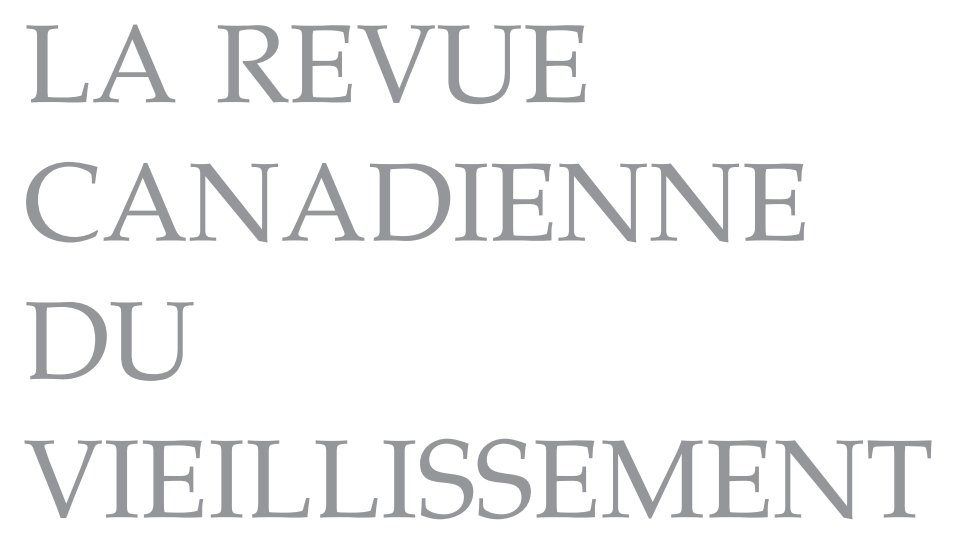

